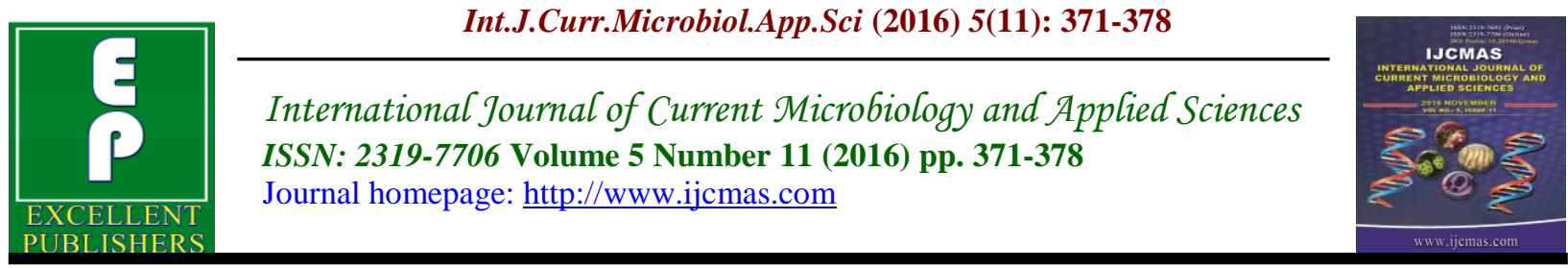

Original Research Article

http://dx.doi.org/10.20546/ijcmas.2016.511.042

\title{
Correlation of Body Mass Index with Low Back Pain amongst Patients without Injury in a Nigeria Population
}

\author{
U.K. Ezemagu ${ }^{1}$, C.I.P Anibeze ${ }^{1}$, C.O. Ani ${ }^{2}$ and G.C Ossi ${ }^{3}$ \\ ${ }^{1}$ Department of Anatomy, Enugu State University of Science and Technology, Nigeria \\ ${ }^{2}$ Department of Radiology, Enugu State University of Science and Technology, Nigeria \\ ${ }^{3}$ Department of Radiology, National Orthopedic Hospital Enugu, Nigeria \\ *Corresponding author
}

\section{Keywords \\ Body mass index, Low back pain, Lumbo-sacral spine, Radiology report, Preliminary diagnosis, Enugu- Nigeria.}

\section{Article Info}

Accepted:

16 October 2016

Available Online:

10 November 2016

\section{A B S T R A C T}

Low back pain in adult population constitutes a major health problem with debilitating consequences on both the sufferer and the society. Initial investigation of the patient with low back pain often includes plain radiography of lumbo-sacral spine. In this study, we tried to establish any correlation between Body Mass Index (BMI) and Low Back Pain (LBP). Identification of any factor which may predispose to or aggravate LBP would be of benefit in the management of the condition. This prospective study of adult out-patients with or without clinical history of low back pain but without injury, referred for lumbo-sacral radiography was conducted at National Orthopedic Hospital and Enugu State University Teaching Hospital both located in Enugu-Nigeria. A total of 114 adult out-patients, including 85 patients with clinical history of LBP was involved. Patient's weight and height was measured with a health scale. Their BMI were calculated and categorized into four groups with patient's age and gender bias as follows: less than $18.5 \mathrm{~kg} / \mathrm{m} 2$ "underweight"; $18.5-25.0 \mathrm{~kg} / \mathrm{m} 2$ "normal weight"; $25.1-30.0 \mathrm{~kg} / \mathrm{m} 2$ "overweight" and above $30 \mathrm{~kg} / \mathrm{m} 2$ "obese". Antero-posterior and lateral radiographs of lumbo-sacral spine of all the patients were assessed and categorized as follows; radiographs with evidence of spinal degenerative changes or other pathologies as positive report and those without as normal report. Data were analyzed using Kruskal-Wallis test for correlation. RESULT- BMI was found to be significantly related to patient's gender and age at $\mathrm{P}<0.01$ and LBP at $\mathrm{P}<0.05$. BMI is a relevant factor of LBP. Increase in BMI leading to overweight or obesity would serve as both aggravator and predictor of LBP. Considering BMI of LBP sufferers without a clear demonstrable etiology could serve as a preliminary diagnosis.

\section{Introduction}

Low back pain may result from alterations from normal biomechanics in the vertebral column and constitutes a major health problem (Giles and Singer, 1997). Pain is always an expression of a disturbance of neurological function. Back injury results from damage, wear, or trauma to the bones, muscles, or other tissues of the back. Common back injuries include sprains and strains, herniated disc and fractured vertebrae. Low back pain of mechanical 
origin may be the result of incorrect lifting habits and posture. Repetitive lifting, bending, and twisting motions of the torso affect both the degree of severity and frequency of low back pain. Low back pain with or without sciatica is second only to the common cold in its frequency (Deyo and Tsui-Wu, 1987). It is a main cause of disability and expense from work related conditions and is a main cause of absence from work (Giles and Singer, 1997). The pattern of musculoskeletal disorders associated with numerous occupations range from upper extremity symptoms to back pain and the risk factors for the occurrence of work-related musculoskeletal disorders include repetitive movement, static posture, physical and workload (Egwu et al., 2006).

Low back pain and injuries attributed to manual lifting activities continue as one of the leading occupational health and safety issues facing preventive medicine (PutzAnderson et al., 1994). Low back pain affects up to $80-88$ percent of the population at sometime during their adult lives with a high prevalence in adults, beginning in adolescence (Althoff et al., 1992). Back pain of mechanical origin is far more prevalent than back pain with an etiology of frank demonstrable pathology (Day et al., 1994).

The most common cause of mechanical back pain is dysfunction of spinal intervertebral joints due to injury, accounting for approximately 72 percent of back pain, while lumbar spondylosis accounts for approximately 10 percent of painful backs (Giles and Singer, 1997). Spondylolysis and spondylolisthesis are the most common cause of low back pain in adolescent athletes. Many other causes of low back pain with or without progressive radiculopathy have been identified including juxtafacet synovial cysts (Tatter and
Cosgrove, 1994). Initial investigation of the patients with low back pain including non specific low back pain and mechanical low back pain, painless lumbar compression fractures or with referred pain to the hip, groin or buttocks, paraplegia and reduced deep tendon reflexes in lower limb, acute urinary retention with or without low back pain and conus medularis syndrome often includes plane radiography of the lumbosacral spine. Also, ideal reference for lumbo-sacral radiography includes osteoporotic collapse in the elderly, inflammatory disorder such as ankylosis spondylitis.

The answer to the complex issue of back pain may well depend upon multidisciplinary co-operation (Giles and Singer, 1997). The identification of any factor which may predispose to or aggravate low back pain would be of benefit in the management of the condition. Therefore this study aims to investigate any relationship between body mass index and low back pain.

\section{Materials and Methods}

This study was approved by the institutional review board of National Orthopedic Hospital and Enugu State University Teaching Hospital. Informed consent was obtained from all patients who participated in this study. This prospective study included a total of 114 out-patients involving 85 patients with clinical history of low back pain, but without accident victims or injury related fractures, referred for lumbo-sacral radiography at National Orthopedic Hospital and Enugu State University Teaching Hospital both located in Enugu-Nigeria. Body Mass Index Measurement and Categorization-The patients' weight and height were measured with a Gulfex Medical and Scientific health 
scale (Model RGZ-120, made in England) considering patient's age and gender and their body mass index (BMI) calculated using the formula $\mathrm{BMI}=\operatorname{mass}(\mathrm{kg}) /$ height $(\mathrm{m})^{2}$. Categorization of BMI was done as follows: less than $18.5 \mathrm{~kg} / \mathrm{m}^{2}$ "underweight"; $18.5-25.0 \mathrm{~kg} / \mathrm{m}^{2}$ "normal weight"; $25.1-30.0 \mathrm{~kg} / \mathrm{m}^{2}$ "overweight" and above $30 \mathrm{~kg} / \mathrm{m}^{2}$ "obese". Radiological Assessment-The Antero-posterior and lateral radiographs of lumbo-sacral spine of all the patients were obtained using computed radiography. An Independent blinded radiological assessment by two consultant radiologists were conducted on the radiographs and identified as follows; radiographs with evidence of spinal degenerative changes or other pathologies as positive report and those without as normal report. Exclusion-Patients (318) with injury and accident victims, more than ever transport related injuries were excluded from this study. Statistical Analysis-The data were analyzed using Kruskal-Wallis test for correlation, with LBP patients assigned "yes" and coded 1 and patients without LBP assigned " no" and coded 2.

\section{Results and Discussion}

Out of 114 patients with requests for X-ray of the lumbo-sacral spine for indications not related to injury or accident, 50 (43.9\%) were males and $64(56.1 \%)$ were females. 85 patients $(74.6 \%)$ had clinical history of low back pain. Amongst the low back pain sufferers $48(56.5 \%)$ were females and 37 $(43.5 \%)$ were males giving a female to male ratio of $1.3: 1$. The mean value of $\mathrm{BMI}$ for patients with low back pain was $27.5 \pm$ $0.6 \mathrm{kgm}^{2}$. 64 patients were with positive reports and 50 patients were with normal reports. Out of 50 patients with normal report, 21 had clinical history of low back pain. The population studied was aged between ages 24 years to 85 years with mean age being 46.5 years. Most of the patients under study who had low back pain were within the age bracket from 34 years to 53 years $(54.2 \%)$ (Table I). BMI was found to be significantly related to patient's gender and age at $\mathrm{P}<0.01$ (Table II). In the population studied, the mean BMI was $26.7 \mathrm{Kgm}^{-2}, 2$ patients $(2 \%)$ were under weight and 42 patients $(37 \%)$ had BMI classified as normal weight. 32 patients (28\%) were overweight while 38 patients (33\%) were found to be obese (Table III). The underweight patients (2) with LBP were with positive report, specifically spina bifida occulta and infectious spondylitis (TB). Amongst the low back pain sufferers there was significant relationship between Body Mass Index and low back pain and the degree of variation $\left(\mathrm{r}^{2}\right)$ in the incidence of LBP attributable to variations in BMI shows $\left(\mathrm{r}^{2}\right)=(-0.193)(-0.193) \%=3.72 \%$ (Table IV). This relationship implies specifically that about $3.72 \%$ of the variations in the incidence of LBP can be attributed to variations in BMI. 21 patients with low back pain whose radiologic findings were classified as normal reports had mean age of 43.6 years and mean BMI of 26.4 \pm $0.88 \mathrm{kgm}^{2}{ }^{2}$ which depict overweight (Table $\mathrm{V})$.

The finding in this study shows that Body Mass Index is not independent of age and gender. BMI and percentage fat relationship are not independent of age and gender (Jackson et al., 2002). Also for the same BMI, the percentage fat of females was 10.4 percent higher than that of males. Modic changes are more likely to be formed in males with a high BMI, who also show disc contour abnormalities, spondylolisthesis or disc degeneration (Arana et al., 2011). Older age has been listed as one of the recognized prognostic factors influencing pain and disability amongst low back pain patients with verified nerve root affection (Jansen $e t$ 
al., 2010). These reports point to the fact that BMI is dependent on age and sex, which supports the findings in this study.

There was statistically significant relationship of BMI with Low back pain in this study. Recall that LBP were coded 1, and without LBP were coded 2. Also, BMI was classified from 1 to 4 with $4=$ "obese". Therefore the negative value of correlation $(r=-0.193)$ implies that an increase in BMI leading to overweight or obesity may result to LBP. Obesity was a strong and independent predictor of recurrent herniated nucleus pulposus after lumbar microdiscectomy, surgeons should incorporate weight loss counseling into their preoperative discussion with patients (Dennis et al., 2010). Interestingly this study specifically indicated the degree of variation between body mass index and occurrence of low back pain and revealed that about $3.72 \%$ $\left(\mathrm{r}^{2}=-0.193 \times-0.193\right)$ of variation in the occurrence of low back pain can be attributable to variation in Body Mass Index. Consequently, the negative value of correlation $(r=-0.193)$ demonstrated that increase in BMI leading to overweight or obesity, may result to LBP. Body Mass Index is proportional to weight and inversely proportional to the square of the height. Weight is transferred from upper extremities and mid section through the low back to lower extremities. Low back pain may result from alterations from normal biomechanics in the vertebral column. Facet cysts are thought to be caused by repetitive trauma and micro-instability producing areas of focal weakness in the facet capsule. Also, juxtafacet cysts can occur throughout the spine but are typically found in mobile segments and especially the lumbar spine, most commonly at the L4-L5 level followed by the L3-L4 and L5-S1 levels in decreasing frequency (Abolfazl 2011). Lumbo-sacral junction supports the weight of the body and transmits same to the ground through pelvic girdle and inferior extremities, also, absorbs shock as a result of the mechanical property of the intervertebral disc. It is clear that mechanical forces are involved in initiating disc degeneration but also have the potential to exert beneficial effects, however, the signaling pathways initiated by mechanical stress and thresholds for these responses have not been elucidated (Sowa et al., 2011). These facts and the findings of this study explicitly implicated increase in Body Mass Index of overweight and obesity as a factor of low back pain in patients without injury related fracture and accident victims.

Probably the low back pain was initiated as a result of transfer of excess weight from upper extremities and mid section in patients with overweight or obesity, especially central obesity, through the low back or lumbo-sacral structures. As such may ultimately alter the biomechanics of lumbar spinal movements and add pressure or shear to the synovial zygapophysial joints, adjacent intervertebral discs or other lumbosacral structures, abnormalities that may contribute to low back pain. This bias was affirmed by the result of patients with low back pain in this study that had their radiologic findings as normal report but had a mean BMI of $26.4 \pm 0.88 \mathrm{kgm}^{-2}$ referred to as overweight (requiring further investigation to provide sufficient clinical information to classify). This suggests that overweight may be an index in low back pain, especially non specific low back pain.

The radiological report showed that patients (64) were with evidence of spinal degenerative changes or other pathologies such as osteoporosis, spondylosis, disc prolapsed etc and patients (50) had normal report. Also, 21 out of 50 patients had normal report with low back pain and patients (29) without low back pain but with request for lumbo-sacral radiography. 
Table.1 Age distribution of LBP Patients

\begin{tabular}{|l|r|r|r|r|}
\hline Valid & \multicolumn{1}{|l|}{ Frequency } & Percent & Valid Percent & \multicolumn{1}{l|}{$\begin{array}{l}\text { Cumulative } \\
\text { Percent }\end{array}$} \\
\hline $24-33$ & 16 & 18.8 & 18.8 & 18.8 \\
$34-43$ & 23 & 27.1 & 27.1 & 45.9 \\
$44-53$ & 23 & 27.1 & 27.1 & 73 \\
$54-63$ & 16 & 18.8 & 18.8 & 91.8 \\
$64-73$ & 4 & 4.7 & 4.7 & 96.5 \\
$74-85$ & 3 & 3.5 & 3.5 & 100.0 \\
Total & 85 & 100.0 & 100.0 & \\
& & & & \\
\hline
\end{tabular}

Table I, shows that $54.2 \%$ with age ranges $34-43$ and 44-53 years have the highest frequencies among the low back pain patients without injury

Table.2 Relationship between BMI and other variables using Kruskal - Wallis test

\begin{tabular}{|l|r|l|l|r|}
\hline & SEX & AGE & HEIGHT & WEIGHT \\
\hline Chi-Square & 13.311 & 11.865 & 15.660 & 47.644 \\
Df & 3 & 3 & 3 & 3 \\
Asymp. Sig & .004 & .008 & .001 & .000 \\
\hline Decision & $\mathrm{P}<0.01$ & $\mathrm{P}<0.01$ & $\mathrm{P}<0.01$ & $\mathrm{P}<0.01$ \\
& Test is highly & Test is highly & Test is highly \\
& significant & significant & Significant & Test is highly \\
& significant \\
\hline
\end{tabular}

Table.3 Kruskal-Wallis Test for Relationship between BMI and LBP Patients

\begin{tabular}{|c|c|c|c|c|c|c|c|c|}
\hline \multirow[t]{2}{*}{ BMI } & \multicolumn{3}{|c|}{ LBP } & \multirow{2}{*}{$\begin{array}{l}\text { Mean } \\
\text { Rank }\end{array}$} & \multirow{2}{*}{$\begin{array}{l}\text { Chi- } \\
\text { Squar } \\
\text { e } \\
\end{array}$} & \multirow[t]{2}{*}{ Df. } & \multirow{2}{*}{$\begin{array}{l}\text { Asymp } \\
\text {. Sig }\end{array}$} & \multirow[t]{2}{*}{ Decision } \\
\hline & YES & NO & $\begin{array}{l}\text { TOTA } \\
\mathrm{L}\end{array}$ & & & & & \\
\hline $\begin{array}{l}\text { Less than } 18.5 \text { (Under } \\
\text { Weight) } \\
18.5-25.0 \text { (Normal) } \\
25.1-20.0 \text { (Over Weight) } \\
\text { Above } 30 \text { (Obese) } \\
\text { Total }\end{array}$ & $\begin{array}{l}2 \\
25 \\
27 \\
31 \\
85\end{array}$ & $\begin{array}{l}0 \\
17 \\
5 \\
7 \\
29\end{array}$ & $\begin{array}{l}2 \\
42 \\
32 \\
38 \\
114\end{array}$ & $\begin{array}{l}43.00 \\
66.07 \\
51.91 \\
53.50\end{array}$ & 8.228 & 3 & .042 & $\begin{array}{l}\mathrm{P}<0.05 \\
\text { Test is } \\
\text { Significan } \\
\mathrm{t}\end{array}$ \\
\hline
\end{tabular}

Kruskal-Wallis Test $\left(\chi^{2}=8.228 ; \mathrm{df}=3 ; \mathrm{p}\right.$-value $\left.=0.042 ; \mathrm{p}<0.05\right)$ 
Table.4 Coefficient of Variation Between BMI and LBP

\begin{tabular}{|l|l|l|l|l|}
\hline & Value & $\begin{array}{l}\text { Asymp. Std. } \\
\text { Error }\end{array}$ & Approx. T & Approx. Sig. \\
\hline Interval by Interval Pearson's R & -.183 & .092 & -1.972 & .051 \\
Ordinal by Ordinal Spearman & -.193 & .093 & -2.077 & .040 \\
$\begin{array}{l}\text { Correlation } \\
\text { N of Valid cases }\end{array}$ & 114 & & & \\
\hline
\end{tabular}

Pearson Chi square test $\left(\chi^{2}=8.301 ; \mathrm{df}=3 ; \mathrm{p}\right.$-value $=0.04$ at $\left.\mathrm{p}<0.05 ; \mathrm{r}=-0.193\right)$

Table.5 Reference Values for Patients with Normal Radiograph and LBP

\begin{tabular}{|l|l|l|l|l|}
\hline & AGE & HIEGHT & WEIGHT & BMI \\
\hline No of Valid cases & 21 & 21 & 21 & 21 \\
Mean & 43.62 & 1.68 & 74.38 & 26.42 \\
Std Error of Mean & 3.17 & .24 & 2.49 & .88 \\
Median & 45.00 & 1.67 & 73.00 & 26.49 \\
Mode & 45.00 & 1.76 & $69.00^{\mathrm{a}}$ & $19.33^{\mathrm{a}}$ \\
Std. Deviation & 14.51 & .11 & 11.39 & 4.05 \\
Variance & 210.55 & .01 & 129.75 & 16.40 \\
Range & 53.00 & .44 & 43.00 & 13.54 \\
Minimum & 16.00 & 1.49 & 53.00 & 19.33 \\
Maximum & 68.00 & 1.93 & 96.00 & 32.87 \\
\hline
\end{tabular}

Multiple modes exist. The smallest value is shown

There is often a discrepancy between the degree of pain and the severity of radiographic changes. For example, disabling zygapophysial joint facet syndromes can be associated with normal or nearly normal plane film radiograph. Also, radiographically normal but painful spines may have painful pathological changes which may be due to mechanical irritation of various pain sensitive soft tissue structures which cannot be visualized by imaging procedure (Giles and Singer, 1997). These deductions from this study suffice to suggest that BMI measurement for LBP patients without a clear demonstrable etiology could serve as a preliminary diagnosis. Also, reducing the number of request for lumbar radiographs for non-specific low back pain patients should be encouraged to avoid unnecessary radiation dose. Nutritional assessment using simple anthropometric parameter of body mass index was recommended for all surgical patients in order to hasten recovery and reduce postoperative morbidity (Ugochukwu and Nwobodo, 2005).

The majority of low back pain sufferers in this study belong to the middle age work force population and this reflects the magnitude of man-hour loss both to the individual and to the society at large. Since low back pain is a main cause of disability and expense from work related conditions and is a main cause of absence from work (Giles and Singer, 1997). Despite efforts at control, including programs directed at both workers and jobs, work-related back injuries still account for a significant proportion of human suffering and economic cost to United States of America (Putz-Anderson et al., 1994). Low back pain with or without 
sciatica is second only to the common cold in its frequency (Deyo and Tsui-Wu, 1987).

Therefore, introduction of reasonable measures aimed at weight reduction for overweight and obese patients will impact positively on management of low back pain and serve as preventive measure for the non sufferer.

\section{Significance of the Result}

Body mass index is a relevant factor in low back pain. Increase in body mass index leading to overweight or obesity might serve as both predictor and aggravator of low back pain. This study specifically indicated the degree of relationship between body mass index and low back pain. Considering BMI of LBP sufferers without a clear demonstrable etiology could serve as a preliminary diagnosis involving simple numeric measure that would allow health professionals to discuss weight problems more objectively with their patients and include weight control strategies in the line of management. Also, reducing the number of request for lumbar radiographs for nonspecific low back pain patients should be encouraged to avoid unnecessary radiation dose.

\section{Acknowledgement}

This study received a grant of 2 million naira $(14,285.71$ at 140 per a dollar exchange rate) from Tertiary Education Tax Fund (Nigeria) through Enugu State University. There is no Conflict of interest.

\section{References}

Abolfazl, R. 2011. Bleeding in a Lumbar Juxtafacet Cyst with Cauda Equina Syndrome: Report of a Case and Review of the Literature. World Spinal Column J., 2(1): 46-51.
Althoff, I., Brinckmann, P., Frobin, W., Sandover, J., Burton, K. 1992. An improved method of stature measurement for quantitative determination of spinal loading. Application to sitting postures and whole body vibration. Spine, 17(6): 682-93.

Arana, E., Kovacs, F.M., Royuela, A et al. 2011. Modic changes and associated features in Southern European Chronic low back pain Patients. Spine J., 11(5): 402- 11.

Day, L.J., Bovill, E.G., Trafton, P.G. 1994. Orthopedics. Current Surgical Diagnosis and Treatment. In Way LW (Eds). Appleton and Lange Pp1011 1104.

Dennis, S., Meredith, Russel, C., Huang, Joseph Nguyen, Stephen Lyman, S. 2010. Analysis of factors that may influence range of motion after cervical disc arthroplasty. Spine J., 10(7): 575-80.

Deyo, R.A. and Tsui-Wu, Y.J. 1987. Descriptive epidemiology of low-back pain and its related medical care in the United States. Spine, 12(3): $264-8$

Egwu, A.O., Ewunonu, E.O., Akpa, A.O.C. et al. 2006. Prevalence of neck, Upper Back and Chest Musculoskeletal symptoms Among Medical Students in Ebonyi State. J. Expt \& Clin Anat. 5 (1): $41-3$

Giles, L.G.F. and Singer, K.P.1997. Clinical Anatomy and Management of Low Back Pain Series, ButterworthHeinemann, Oxford Pp1, 11: 35-68.

Jackson, A.S., Stanforth, P.R., Wilmore, J.H. et al. 2002. The effect of sex, age and race on estimating percentage body fat from body mass index: The heritage family study. Int. J. Obes. Relat. Metab. Disord., 26(6): 789-96.

Jansen, K., Ole, Nielsen, V., Claus, Kristian Stengaard-Pedersen. 2010. One year 
prognosis in sick listed low back pain patients with and without radiculopathy. Prognostic factors influencing pain and disability. Spine $J ., 10(8): 659-75$.

Putz-Anderson Vern, Thomas, R., Waters, Arun Garg. 1994. Applications Manual for the Revised NIOSH Lifting Equation. (DHHS) NIOSH Publication, $94-110$.

Sowa, G.A., Coelho, J.P., Bell, K.M. et al. 2011. Alterations in gene expression in response to compression of nucleus Pulposus cells. Spine J., 11(1): 36-43. Tatter, S.B., Cosgrove, G.R. 1994 Hemorrhage into a lumbar synovial cyst causing an acute cauda equina syndrome. Case report. J. Neurosurg., 81: 449-52.

Ugochukwu, A.I. and Nwobodo, N. 2005. The Relevance of Simple Anthropometric Parameter of Body Mass Index in Assessing Nutritional Status of Surgical Patients. J. Expt. \& Clin. Anat., 4(2): 29-31.

\section{How to cite this article:}

Ezemagu, U.K., C.I.P Anibeze, C.O. Ani and Ossi, G.C. 2016. Correlation of Body Mass Index with Low Back Pain amongst Patients without Injury in a Nigeria Population. Int.J.Curr.Microbiol.App.Sci. 5(11): 371-378. doi: http://dx.doi.org/10.20546/ijcmas.2016.511.042 